BMJ Paediatrics Open

\section{Fatigue among children with a chronic disease: a cross-sectional study}

To cite: Nap-van der Vlist MM, Dalmeijer GW, Grootenhuis MA, et al. Fatigue among children with a chronic disease: a cross-sectional study. BMJ Paediatrics Open 2021;5:e000958. doi:10.1136/ bmjpo-2020-000958

Received 23 November 2020 Revised 8 January 2021 Accepted 3 February 2021

Check for updates

(c) Author(s) (or their employer(s)) 2021. Re-use permitted under CC BY-NC. No commercial re-use. See rights and permissions. Published by BMJ.

${ }^{1}$ Social Paediatrics, Wilhelmina Children's Hospital University Medical Centre, Utrecht, The Netherlands

${ }^{2}$ Division management, Julius Center for Health Sciences and Primary Care, Utrecht, The Netherlands

${ }^{3}$ Psycho-Oncology, Princess Maxima Center for Pediatric Oncology, Utrecht, The Netherlands

${ }^{4}$ Cystic Fibrosis Center and Department of Pediatric Respiratory Medicine, University Medical Center Utrecht, Utrecht, The Netherlands

${ }^{5}$ Solid Tumours, Princess Maxima Center for Pediatric Oncology, Utrecht, The Netherlands

${ }^{6}$ Paediatric Rheumatology, Wilhelmina Children's Hospital University Medical Centre, Utrecht, The Netherlands

Correspondence to

Merel M Nap-van der Vlist; m.m. vandervlist-3@umcutrecht.nl

\section{ABSTRACT}

Objective To determine: (1) which biological/lifestyle, psychological and/or social factors are associated with fatigue among children with a chronic disease and (2) how much each of these factors contributes to explaining variance in fatigue.

Design and setting This was a cross-sectional study across two children's hospitals.

Patients We included children aged 8-18 years who visited the outpatient clinic with cystic fibrosis, an autoimmune disease or postcancer treatment.

Main outcome measures Fatigue was assessed using the PedsQL Multidimensional Fatigue Scale. Generic biological/lifestyle, psychological and social factors were assessed using clinical assessment tools and questionnaires. Multiple linear regression analyses were used to test the associations between these factors and fatigue. Finally, a multivariable regression model was used to determine which factor(s) have the strongest effect on fatigue.

Results A total of 434 out of 902 children were included ( $48 \%$ participation rate), with a median age of 14.5 years; $42 \%$ were male. Among these 434 children, $21.8 \%$ were severely fatigued. Together, all biopsychosocial factors explained $74.6 \%$ of the variance in fatigue. More fatigue was uniquely associated with poorer physical functioning, more depressive symptoms, more pressure at school, poorer social functioning and older age.

Conclusions Fatigue among children with a chronic disease is multidimensional. Multiple generic biological/ lifestyle, psychological and social factors were strongly associated with fatigue, explaining $58.4 \% ; 65.8 \%$ and $50.0 \%$ of the variance in fatigue, respectively. Altogether, almost three-quarters of the variance in fatigue was explained by this biopsychosocial model. Thus, when assessing and treating fatigue, a transdiagnostic approach is preferred, taking into account biological, psychological and social factors.

\section{INTRODUCTION}

Children who grow up with a chronic disease often face a number of challenges. One of the most prevalent challenges is fatigue, which can cause major disruptions in the child's development and social participation. ${ }^{1-4}$ Fatigue can be triggered by inflammation or the start of a therapeutic regimen, among other factors ${ }^{156}$; however, fatigue can persist

\section{What is known about the subject?}

Fatigue is relatively common among children with a chronic disease, but can only be partially explained by disease-related factors.

\section{What this study adds?}

- Fatigue is a multidimensional concept spanning paediatric chronic diseases, with strong, overlapping correlations with biological, psychological and social factors.

- Therefore, these factors should be taken in account when assessing and treating fatigue in this patient population.

and cause distress even in children with lowor absent—disease activity. ${ }^{4}$ Importantly, factors other than disease-specific biological factors can explain fatigue; indeed, according to the biopsychosocial model, a number of potentially modifiable generic biological/ lifestyle, psychological and/or social factors can be associated with-and can perpetuate-fatigue in these patients. ${ }^{14-689}$ Therefore, understanding fatigue in children with chronic disease, as well as the factors that can cause or perpetuate this fatigue, may require a transdiagnostic approach. ${ }^{1011}$

Transdiagnostic can be defined as an approach in which clinicians aim to go beyond the disease-specific biological factors of a disease and look for generic factors. ${ }^{10}$ For example, pain, sleep and physical activity are potentially modifiable biological or lifestyle factors that are transdiagnostic or generic. ${ }^{135712}$ Moreover, modifiable transdiagnostic psychological and social factors such as depressive symptoms, anxiety and disturbances in the family dynamic have been associated with fatigue. ${ }^{1813}$ However, whether fatigue-perpetuating factors in children with chronic disease are indeed transdiagnostic is an open question, as most studies focused on a single disease. ${ }^{3-5}$ Knowledge regarding the 
relationship between fatigue and lifestyle, mental and social factors is particularly relevant, as it can not only help clinicians treat children with a chronic disease, but will also increase our understanding of other fatiguerelated syndromes such as fatigue experienced following COVID-19. ${ }^{14}$

Therefore, we aimed to determine: (1) which modifiable factors (eg, biological/lifestyle, psychological and/ or social) are associated with fatigue across various paediatric chronic diseases and (2) how much each of these factors contributes to explaining the variance in fatigue.

\section{METHODS}

\section{Study design}

In this cross-sectional study, participating children completed questionnaires prior to their outpatient visit at the Wilhelmina Children's Hospital or the Princess Máxima Centre for Paediatric Oncology in Utrecht, the Netherlands. At the time of the outpatient visit, clinical data were obtained to describe the child's disease activity and duration. Participants were recruited through the PROactive study. ${ }^{2}$ Informed consent to use the data from the questionnaires and to extract data from the child's medical records was obtained from both the child and his/her parent(s).

\section{Patient and public involvement}

Patient organisations were involved in setting the agenda and the priorities for this research. Several choices in the design were reviewed by patient representatives. Patients and the public were not involved in the conduct of the study. We added qualitative research methods to our research line in order to stress the patient's and parent's perspective. Patient organisations and societal partners are involved in the dissemination of our research.

\section{Participants}

Children aged 8-18years with cystic fibrosis (CF), an autoimmune disease, or postcancer treatment were recruited from the PROactive study, in which they were included from December 2016 through February 2020. The lower age limit was chosen because we aimed to investigate selfreported fatigue. The group of children with an autoimmune disease included children with an immunodeficiency disorder, an autoinflammatory condition, or an autoimmune disease in the strictest sense. To best assess which transdiagnostic factors are associated with fatigue, we included children who were at least 1-year postdiagnosis (the CF and autoimmune disease groups) or who were within 1 year after completing their cancer treatment. This was done as disease-specific factors, such as disease activity (generally highest in the first year after diagnosis), receiving the diagnosis, starting treatment and the disease itself can cause significant fatigue in the first year postdiagnosis or during the cancer treatment.

\section{Study procedures}

Families were approached by email 3 weeks before a regularly scheduled outpatient visit. All questionnaires were completed by the child via a web-based portal (www.hetklikt.nu), with parental assistance if needed. As needed, the families were reminded once via email and/or once via telephone. A research team was available to answer questions. The questionnaires were linked to each patient's clinical assessment during the outpatient visit. The estimated time participants needed to complete all questionnaires was $30-45 \mathrm{~min}$. They were not presented in a random order, but attention was paid that different topics were alternated.

\section{Measurements}

The primary outcome measurement was the child's self-reported fatigue, which was measured using the general fatigue subscale of the validated PedsQL Multidimensional Fatigue Scale (PedsQL MFS), which has good internal consistency. ${ }^{15}$ In the national population norm, the reported mean values for this general fatigue subscale are 82.66 (95\% CI 80.53 to 84.80 ) and 76.72 (95\% CI 74.44 to 78.99 ) for children aged 8-12years and 13-18years, respectively. ${ }^{15}$ For descriptive statistics, severe fatigue was defined as a score greater than 2 SDs below the norm, taking into account both sex and age categories (ie, 8-12 and 13-18years). ${ }^{2}$

To characterise our sample, we collected the following variables from the child's medical record: age, sex, time elapsed between diagnosis and assessment, and disease activity at assessment. In the CF group, disease activity was measured using forced expiratory volume in $1 \mathrm{~s}$ $\left(\mathrm{FEV}_{1}\right)$, expressed as a percentage of predicted $\mathrm{FEV}_{1} \cdot{ }^{16}$ For patients with juvenile idiopathic arthritis (JIA), the validated clinical Juvenile Arthritis Disease Activity Score and erythrocyte sedimentation rate (ESR) were used as a proxy for disease status; only ESR was used for participants with other autoimmune or autoinflammatory diseases. ${ }^{17}$ All children in the postcancer treatment group were in complete remission.

For all questionnaires and tools used in our study, the number of items, range, interpretation and Cronbach's alpha are provided in table 1. In this study, we only used validated concepts and (sub)scales that could be compared with outcomes of other studies with healthy children or children with other diseases.

\section{Generic biological/lifestyle factors}

The following generic biological/lifestyle factors were measured: pain, sleep difficulties, physical functioning, physical activity and body mass index (BMI). Pain was measured using a Visual Analogue Scale, reflecting the average pain experienced in the previous week. ${ }^{18}$ To measure sleep difficulties and physical activity, we used questions from the Health Behaviour in School Children (HBSC) questionnaire. ${ }^{192}$ The physical activity score is based on the WHO's recommendation; this measure has an acceptable level of reliability. ${ }^{21}{ }^{22}$ Physical functioning 
Table 1 Summary of the factors assessed in this study and features of the corresponding questionnaires/tools

\begin{tabular}{|c|c|c|c|c|c|}
\hline Assessed factor & Questionnaire & Construct/subscale & Items & Range/replies & $\begin{array}{l}\text { Cronbach's } \\
\text { alpha }\end{array}$ \\
\hline Fatigue & PedsQL MFS* & General fatigue subscale & 6 & $\begin{array}{l}0-100: \text { higher score=less } \\
\text { fatigue }\end{array}$ & 0.90 \\
\hline Pain & $\begin{array}{l}\text { Visual Analogue } \\
\text { Scale† }\end{array}$ & N/A & 1 & $\begin{array}{l}0-10: \text { higher score=more } \\
\text { pain }\end{array}$ & $\mathrm{N} / \mathrm{A}$ \\
\hline Sleep difficulties & HBSC $\neq$ & $\begin{array}{l}\text { In the last } 6 \text { months, how often } \\
\text { have you had difficulties getting } \\
\text { to sleep? }\end{array}$ & 1 & $\begin{array}{l}\text { Rarely or never; about every } \\
\text { month; about every week; } \\
\text { more than once a week; } \\
\text { about every day }\end{array}$ & N/A \\
\hline $\begin{array}{l}\text { o of days } \\
\text { physically active }\end{array}$ & HBSC $\ddagger$ & $\begin{array}{l}\text { Over the past } 7 \text { days, on how } \\
\text { many days were you physically } \\
\text { active for a total of at least } \\
60 \text { min per day? }\end{array}$ & 1 & 0-7 days per week & $\mathrm{N} / \mathrm{A}$ \\
\hline $\begin{array}{l}\text { Physical } \\
\text { functioning }\end{array}$ & PedsQL GCS§ & Physical functioning subscale & 8 & $\begin{array}{l}0-100: \text { higher score=better } \\
\text { functioning }\end{array}$ & 0.89 \\
\hline $\begin{array}{l}\text { Depressive } \\
\text { symptoms }\end{array}$ & RCADSף & $\begin{array}{l}\text { Major depressive disorder } \\
\text { subscale }\end{array}$ & 10 & $\begin{array}{l}0-30 \text { : higher score=more } \\
\text { depressive symptoms }\end{array}$ & 0.85 \\
\hline Anxiety & RCADSף & Total anxiety subscale & 37 & $\begin{array}{l}0-111 \text { : higher score=more } \\
\text { anxiety }\end{array}$ & 0.94 \\
\hline $\begin{array}{l}\text { Pain } \\
\text { catastrophising }\end{array}$ & PCS-C** & N/A & 13 & $\begin{array}{l}0-52: \text { higher } \\
\text { score=more pain } \\
\text { catastrophising }\end{array}$ & 0.91 \\
\hline $\begin{array}{l}\text { Emotional } \\
\text { functioning }\end{array}$ & PedsQL GCS§ & Emotional functioning subscale & 5 & $\begin{array}{l}0-100 \text { : higher score=better } \\
\text { functioning }\end{array}$ & 0.79 \\
\hline $\begin{array}{l}\text { Pressure at } \\
\text { school }\end{array}$ & HBSC $\ddagger$ & $\begin{array}{l}\text { How pressured do you feel by } \\
\text { the schoolwork you have to do? }\end{array}$ & 1 & $\begin{array}{l}\text { Not at all; a little; quite } \\
\text { some; a lot }\end{array}$ & $\mathrm{N} / \mathrm{A}$ \\
\hline Being bullied & HBSC $\ddagger$ & $\begin{array}{l}\text { How often have you been } \\
\text { bullied at school over the last } \\
\text { couple of months? }\end{array}$ & 1 & $\begin{array}{l}\text { Never; one or two times in } \\
\text { the past month; two or three } \\
\text { times a month; about once a } \\
\text { week; a few times a week }\end{array}$ & $\mathrm{N} / \mathrm{A}$ \\
\hline $\begin{array}{l}\text { Communication at } \\
\text { home }\end{array}$ & HBSC $\ddagger$ & $\begin{array}{l}\text { Communication at home } \\
\text { subscale }\end{array}$ & 4 & $\begin{array}{l}\text { 1-5: higher score=better } \\
\text { communication }\end{array}$ & 0.80 \\
\hline Support at home & HBSC $\neq$ & Support at home subscale & 4 & $\begin{array}{l}1-7: \text { higher score=more } \\
\text { support at home }\end{array}$ & 0.92 \\
\hline $\begin{array}{l}\text { Support by } \\
\text { friends }\end{array}$ & HBSC $\ddagger$ & Support from friends subscale & $\begin{array}{l}3 \text { (8-11 years) or } 4 \\
\text { (12-18years old) }\end{array}$ & $\begin{array}{l}\text { 1-7: higher score=more } \\
\text { support from friends }\end{array}$ & 0.95 \\
\hline Social functioning & PedsQL GCS§ & Social functioning subscale & 5 & $\begin{array}{l}0-100: \text { higher score=better } \\
\text { functioning }\end{array}$ & 0.75 \\
\hline $\begin{array}{l}\text { Member of a } \\
\text { sports team or } \\
\text { club }\end{array}$ & HBSC $\ddagger$ & $\begin{array}{l}\text { Are you a member of a sport } \\
\text { community or club? }\end{array}$ & 1 & Member; not a member & $\mathrm{N} / \mathrm{A}$ \\
\hline Screen time & HBSC $\ddagger$ & $\begin{array}{l}\text { About how many hours a day } \\
\text { do you usually watch television } \\
\text { in your free time during week } \\
\text { and weekend days? } \\
\text { About how many hours a day } \\
\text { do you usually play games on } \\
\text { a computer or game console in } \\
\text { your free time during week and } \\
\text { weekend days? }\end{array}$ & 4 & $\begin{array}{l}\text { None at all; about half an } \\
\text { hour a day; about } 1 \text { hour a } \\
\text { day; about } 2 \text { hours a day; } \\
\text { about } 3 \text { hours a day; about } \\
4 \text { hours a day; about } 5 \text { hours } \\
\text { a day; about } 7 \text { or more } \\
\text { hours a day }\end{array}$ & 0.75 \\
\hline
\end{tabular}

*Adapted from Gordijn et al. ${ }^{15}$

†Adapted from Rosier et al. ${ }^{18}$

†Adapted from Currie et al..$^{19}$

§Adapted from Engelen et al. ${ }^{23}$

ๆAdapted from Kösters et al. ${ }^{25}$

${ }^{* \star}$ Adapted from Crombez et al. ${ }^{26}$

GCS, General Core Scale; MFS, Multidimensional Fatigue Scale ; N/A, not available; PCS-C, Pain Catastrophising Scale for Children;

RCADS, Revised Child Anxiety and Depression Scale. 
Table 2 Baseline characteristics of the paediatric patients included in the study

\begin{tabular}{|c|c|c|c|}
\hline & Children with CF & $\begin{array}{l}\text { Children with autoimmune } \\
\text { disease }\end{array}$ & $\begin{array}{l}\text { Postcancer treatment } \\
\text { patients }\end{array}$ \\
\hline Filled out questionnaires & $\mathrm{N}=71$ & $\mathrm{~N}=262$ & $\mathrm{~N}=101$ \\
\hline Age, years (median (IQR)) & $15.3(12.8-17.0)$ & $14.4(11.6-16.4)$ & $13.6(10.5-16.6)$ \\
\hline Male sex, N (\%) & $35(49.3)$ & 97 (37.0) & $50(49.5)$ \\
\hline $\begin{array}{l}\text { PedsQL General Fatigue Score, } \\
\text { median (IQR) }\end{array}$ & $75.0(54.2-87.5)$ & $75.0(54.2-88.5)$ & $75.0(50.0-91.7)$ \\
\hline Severely fatigued, N (\%) & $15(21.1)^{\star}$ & $54(20.6)^{\star}$ & $26(26.7)^{\star}$ \\
\hline $\begin{array}{l}\text { Consented to use information } \\
\text { in the child's medical record }\end{array}$ & $\mathrm{N}=70$ & $\mathrm{~N}=\mathbf{2 4 5}$ & $\mathrm{N}=93$ \\
\hline BMI, median (IQR) & $18.4(16.7-20.3)$ & $19.2(17.0-21.9)$ & $19.1(16.4-21.1)$ \\
\hline Diagnosis, N (\%) & $\begin{array}{l}43(61 \%) \text { homozygote } \\
\text { dF508; } \\
26(37 \%) \text { heterozygote } \\
\text { dF508; } \\
1(1 \%) \text { other }\end{array}$ & $\begin{array}{l}37(15 \%) \text { polyarticular JIA; } \\
83(34 \%) \text { oligoarticular JIA; } \\
12(5 \%) \text { systemic JIA; } \\
31(13 \%) \text { other form of JIA; } \\
35(14 \%) \text { immunodeficiency; } \\
16(7 \%) \text { autoinflammatory } \\
\text { condition; } \\
31(13 \%) \text { systemic autoimmune } \\
\text { disease }\end{array}$ & $\begin{array}{l}32(34 \%) \text { solid tumour; } \\
52(56 \%) \text { leukaemia/ } \\
\text { lymphoma; } \\
9(10 \%) \text { brain tumour }\end{array}$ \\
\hline $\begin{array}{l}\text { Duration of disease status, } \\
\text { years } \dagger\end{array}$ & $15.3(12.8-17.0)$ & $6(3-9)$ & $0.4(0.2-0.7)$ \\
\hline Disease activity $†$ & $\mathrm{FEV}_{1} \%: 86.1 \pm 17.6$ & $\begin{array}{l}\text { cJADAS: } 0.5(0-4)(n=144) \\
\text { ESR: } 4 \text { mm/1st hr }(2-7)(n=222)\end{array}$ & $\begin{array}{l}\text { All less than 1-year post- } \\
\text { treatment }\end{array}$ \\
\hline
\end{tabular}

If the data were normally distributed, the mean $\pm S D$ is given; if not, the median and IQR is given.

${ }^{*}$ Based on cut-offs as defined in Nap-van der Vlist et al. ${ }^{2}$

†Disease duration: years since diagnosis until inclusion for children with JIA; years from end of treatment until inclusion for children postcancer treatment.

BMI, body mass index; CF, cystic fibrosis; cJADAS, clinical Juvenile Arthritis Disease Activity Score; ESR, erythrocyte sedimentation rate;

$\mathrm{FEV}_{1} \%$, predicted percentage of forced expiratory volume in $1 \mathrm{~s}$; JIA, juvenile idiopathic arthritis; NA, not applicable.

was assessed using a subscale of the PedsQL General Core Scale (PedsQL GCS); this instrument has good validity and reliability. ${ }^{23}$ BMI was extracted from the child's medical record. For the regression analyses, the z-scores of BMI were used. ${ }^{24}$

\section{Psychological factors}

Psychological factors included depressive symptoms, anxiety, emotional functioning and pain catastrophising. Depressive symptoms and anxiety were measured using the respective subscales of the Revised Child Anxiety and Depression Scale, which has good internal consistency. ${ }^{25}$ Both scores correspond to the symptoms of childhood anxiety and depressive disorders in the Diagnostic and Statistical Manual of Mental Disorders IV. Emotional functioning was measured using the PedsQL GCS. ${ }^{23}$ Pain catastrophising was measured using the Pain Catastrophising Scale for Children, which has good internal consistency. ${ }^{26}$

\section{Social factors}

Social factors included communication and support at home, support by friends, being a member of a sports team or club, social functioning, pressure at school, being bullied and screen time. Social functioning was measured using the PedsQL GCS ${ }^{23}$; all other factors were included in the HBSC questionnaire. ${ }^{19}$ Screen time was assessed using four questions regarding how much the child watched movies and/or shows and played computer games, calculated as a daily average.

\section{Data analyses}

Descriptive statistics were used to describe the children in the various disease groups. Normally distributed data are presented at the mean $\pm \mathrm{SD}$; otherwise median and IQR are provided. Differences between participants and nonparticipants, between completers and non-completers, and between disease groups were analysed using the Student's t-test, Kruskal-Wallis test or $\chi^{2}$ test. First, multiple linear regressions were used to test the putative associations, with fatigue as the dependent variable and each generic biological/lifestyle, psychological and social factor as the independent variable. All 16 regressions were adjusted for the child's age and sex, as these are known to be important determinants of fatigue. ${ }^{27}$ The assumptions for linear regression analysis were tested, including linearity between the dependent and independent variable, homoscedasticity, and normality of the residuals. Multicollinearity between the separate biopsychosocial factors 
Table 3 Linear regression per factor with dependent variable fatigue (PedsQL MFS general fatigue scale) for the entire group of children with chronic diseases, adjusted for sex and age

\begin{tabular}{|c|c|c|c|}
\hline Associated modifiable factors & Unstandardised $\beta$ & Effect size & $95 \% \mathrm{Cl}$ \\
\hline \multicolumn{4}{|l|}{ Biological/lifestyle factors } \\
\hline \multicolumn{4}{|l|}{ Factors associated with more fatigue } \\
\hline Pain (VAS, range 0-10) & -4.0 & -0.5 & -4.7 to $-3.4^{\star \star}$ \\
\hline Difficulties getting to sleep (0-5; 'never' to 'almost every day') & -6.1 & -0.4 & -7.4 to $-4.9^{\star *}$ \\
\hline \multicolumn{4}{|l|}{ Factors associated with less fatigue } \\
\hline No of days physically active/week (0-7) & 1.8 & 0.2 & 0.9 to $2.8^{\star \star}$ \\
\hline Physical functioning (PedsQL GCS subscale, range 0-100) & 0.7 & 0.7 & 0.7 to $0.8^{* *}$ \\
\hline \multicolumn{4}{|l|}{ Factors not associated with fatigue } \\
\hline BMI z-score & -1.2 & -0.1 & -3.3 to 0.8 \\
\hline \multicolumn{4}{|l|}{ Psychological factors } \\
\hline \multicolumn{4}{|l|}{ Factors associated with more fatigue } \\
\hline Depressive symptoms (RCADS, range 0-30) & -3.9 & -0.8 & -4.2 to $-3.6^{\star *}$ \\
\hline Anxiety level (RCADS, range 0-111) & -0.9 & -0.5 & -1.1 to $-0.8^{* *}$ \\
\hline Pain catastrophising (PCS-C, range 0-52) & -1.2 & -0.5 & -1.4 to $-1.0^{\star *}$ \\
\hline \multicolumn{4}{|l|}{ Factors associated with less fatigue } \\
\hline Emotional functioning (PedsQL GCS, range 0-100) & 0.7 & 0.6 & 0.6 to $0.8^{\star *}$ \\
\hline \multicolumn{4}{|l|}{ Social factors } \\
\hline \multicolumn{4}{|l|}{ Factors associated with more fatigue } \\
\hline Pressure at school (0-4; 'not at all' to 'a lot') & -8.8 & -0.3 & -11.2 to $-6.4^{\star *}$ \\
\hline Being bullied (0-5; 'never' to 'several times per week') & -4.2 & -0.1 & -7.7 to $-0.8^{*}$ \\
\hline \multicolumn{4}{|l|}{ Factors associated with less fatigue } \\
\hline Communication at home ( $1-5$, higher score=better communication) & 4.9 & 0.1 & 1.7 to $8.2^{\star \star}$ \\
\hline Support at home (1-7, higher score=more support) & 2.8 & 0.1 & 0.8 to $4.8^{\star \star}$ \\
\hline Support by friends $(1-7$, higher score=more support) & 3.4 & 0.2 & 1.9 to $5.0^{\star \star}$ \\
\hline Social functioning (PedsQL GCS subscale, range 0-100) & 0.9 & 0.6 & 0.8 to $1.0^{\star \star}$ \\
\hline Member of a sports team or club ( $0=$ not a member, $1=$ member $)$ & 9.2 & 0.2 & 4.8 to $13.6^{\star *}$ \\
\hline \multicolumn{4}{|l|}{ Factors not associated with fatigue in this sample } \\
\hline Screen time per day (hours/day) & -1.2 & -0.1 & -2.8 to 0.4 \\
\hline
\end{tabular}

The PedsQL MFS is scored on a scale from 0 to 100, with a lower score indicating more severe fatigue. Thus, a negative correlation indicates a lower score, thus indicating more fatigue.

${ }^{*} \mathrm{P}<0.05,{ }^{* *} \mathrm{p}<0.01$.

BMI, body mass index; PCS-C, Pain Catastrophising Scale for Children; PedsQL GCS, PedsQL Generic Core Scale; PedsQL MFS, PedsQL Multidimensional Fatigue Scale; RCADS, Revised Child Anxiety and Depression Scale; VAS, Visual Analogue Scale.

was ruled out. Second, we investigated whether the associations differed between disease groups by adding a variable of the interaction between disease group and the tested independent variable to the regression model. Third, we built four multivariable linear regression models using: (1) all generic biological/lifestyle factors, (2) all psychological factors, (3) all social factors and (4) all biopsychosocial factors; we then used these four models to describe the variance in fatigue explained by the generic biological/lifestyle, psychological and social variables. The associations were described using the unstandardised beta, effect size (standardised beta) and 95\% CI. Effects were assessed in relation to $\mathrm{p}$ values, effect sizes, adjusted $\mathrm{R}^{2}$ and the Akaike information criterion.
Disease-specific characteristics were not included in the models, as the aim of the study was to describe modifiable, perpetuating factors that go beyond disease-specific variables, given that disease activity was generally low or absent in this sample. To correct for multiple testing, a $\mathrm{p}<0.01$ was considered statistically significant in all analyses. Effect sizes $\geq 0.2, \geq 0.5$ and $\geq 0.8$ were considered small, moderate and large, respectively.

\section{RESULTS}

Patient characteristics

Among the 902 children who were approached, 434 (48\%) participated; 409 of these 434 participating 


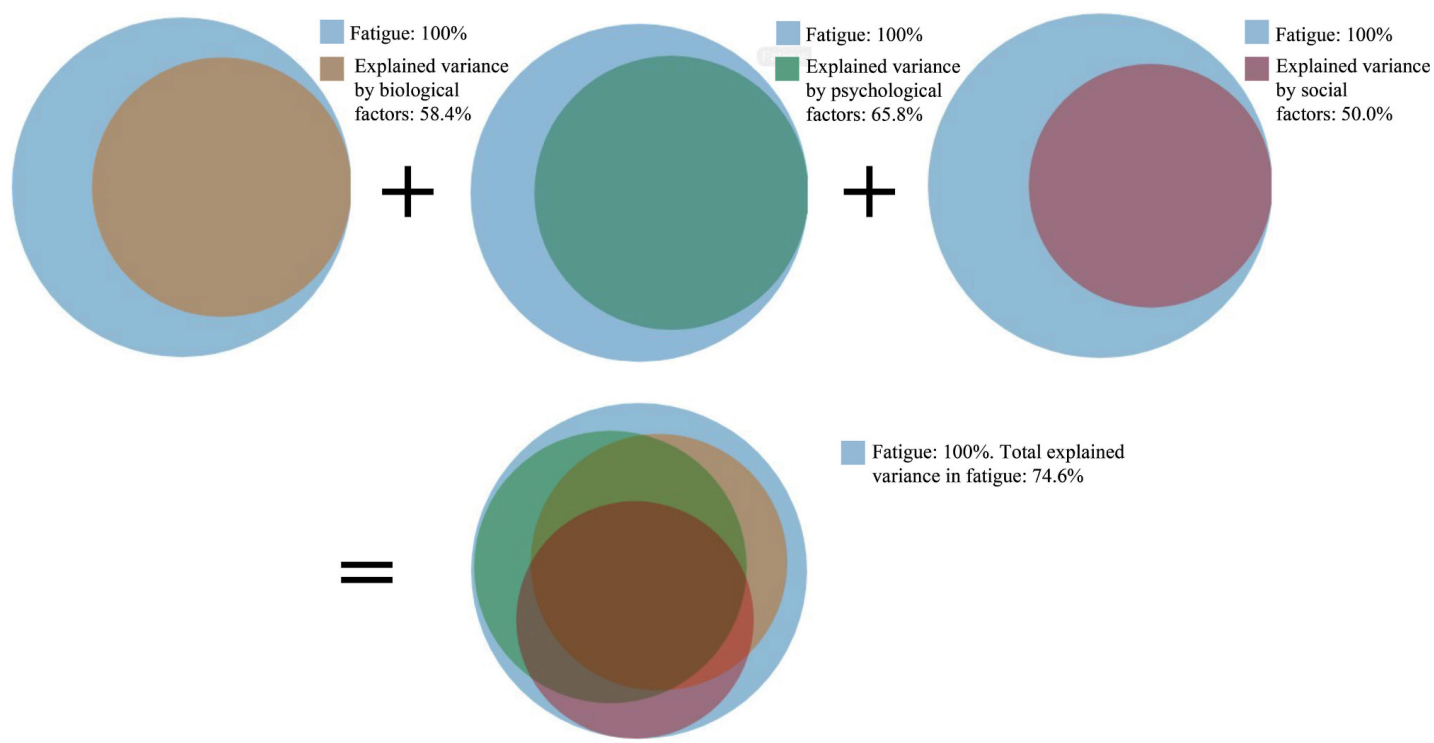

Figure 1 Graphical overview of the explained variance in fatigue by biological, psychological and social factors.

families $(94 \%)$ also provided informed consent for the use of data from the child's medical record. We found no difference between the 434 participants and the 468 non-participants with respect to age or sex. Although all 434 participants reported their fatigue score, only 357 participants completed all assessments in their entirety, with no significant differences in fatigue scores between completers and non-completers. The most commonly cited reasons for not participating were personal circumstances and current participation in other research.

Among the 434 participating children, 71 had CF, 262 had an autoimmune disease and 101 were postcancer treatment patients (table 2); we found no significant difference between these three groups with respect to age or sex. The median score (IQR) on the PedsQL MFS general fatigue subscore was 75.0 (54.2-87.5), 75.0 (54.2-88.5) and 75.0 (50.0-91.7) for the CF, autoimmune and postcancer treatment groups, respectively, with $21.1 \%, 20.6 \%$ and $26.7 \%$ of children, respectively, scoring as severely fatigued. When only age and sex were entered into a model with fatigue as dependent variable, girls reported more fatigue than boys $(\mathrm{p}<0.01)$, and older children reported more fatigue than younger children $(\mathrm{p}<0.01)$.

\section{Association between biopsychosocial factors and fatigue}

Among the entire group of participating children with chronic disease, all of the generic biological/lifestyle, psychological and social factors were significantly associated with fatigue, with three exceptions: BMI, being bullied and the amount of screen time (table 3). We found no significant differences between the three disease groups with respect to the association between fatigue and the generic biological/lifestyle, psychological or social factors.

\section{Regression models}

The first regression model, entering all of the generic biological/lifestyle factors (ie, pain, sleep difficulties, physical activity, and physical functioning), explained $58.4 \%$ of the variance in fatigue. Entering all of the psychological factors (ie, depressive symptoms, anxiety, emotional functioning and pain catastrophising) into a second regression model explained $65.8 \%$ of the variance in fatigue. In the depression subscale, two of the ten items are related to feeling fatigued; however, removing these two items did not substantially change the results. The third model, entering all of the social variables (ie, communication at home, support at home, support by friends, being a member of a sports team or club, social functioning, pressure at school, being bullied and screen time), explained $50.0 \%$ of the variance in fatigue. Lastly, entering all generic biological/lifestyle, psychological and social factors into a composite model revealed substantial overlap in the amount of variance explained by these domains, with this full model explaining $74.6 \%$ of the variance in fatigue (figure 1 and table 4 ).

The complete model revealed that the following factors were significantly associated with more fatigue: poorer physical functioning ( $\beta=0.3,95 \%$ CI: 0.2 to 0.4 ), more depressive symptoms $(\beta=-2.6,95 \% \mathrm{CI}:-3.1$ to -2.1$)$, more pressure at school $(\beta=-2.8,95 \%$ CI: -4.4 to -1.2$)$, poorer social functioning ( $\beta=0.2,95 \%$ CI: 0.1 to 0.3$)$ and older age $(\beta=-0.9,95 \%$ CI: -1.3 to -0.4$)$. The complete model is shown in table 5 .

\section{DISCUSSION}

Our results indicate that fatigue in paediatric chronic disease is strongly associated with several transdiagnostic, potentially modifiable generic biological/lifestyle, psychological and social factors, factors that can be addressed with interventions. We found substantial 
Table 4 Overview of three models: one model including all generic biological/lifestyle factors, one model containing all psychological factors and one model containing all social factors

\begin{tabular}{|c|c|c|c|}
\hline Associated factors & Unstandardised $\beta$ & Effect size & $95 \% \mathrm{Cl}$ \\
\hline \multicolumn{4}{|l|}{ Model 1. Biological/lifestyle factors ( $N=413$, adj. $\mathrm{R} 258.4 \%$ ) } \\
\hline \multicolumn{4}{|l|}{ Factors associated with more fatigue } \\
\hline Pain (VAS, range 0-10) & -1.1 & -0.1 & -1.7 to $-0.5^{\star *}$ \\
\hline Difficulties getting to sleep ( $0-5$; 'never' to 'almost every day') & -3.3 & -0.2 & -4.3 to $-2.4^{\star *}$ \\
\hline \multicolumn{4}{|l|}{ Factors associated with less fatigue } \\
\hline No of days physically active/week (0-7) & 0.4 & 0.0 & -0.3 to 1.1 \\
\hline Physical functioning (PedsQL GCS subscale, range 0-100) & 0.6 & 0.5 & 0.5 to $0.7^{\star \star}$ \\
\hline \multicolumn{4}{|l|}{ Model 2. Psychological factors (n=370, adj. R2 65.8\%) } \\
\hline \multicolumn{4}{|l|}{ Factors associated with more fatigue } \\
\hline Depressive symptoms (RCADS, range 0-30) & -3.5 & -0.7 & -4.0 to $-3.0^{\star *}$ \\
\hline Anxiety level (RCADS, range $0-111)$ & 0.3 & 0.2 & 0.1 to $0.4^{\star \star}$ \\
\hline Pain catastrophising (PCS-C, range 0-52) & -0.3 & 0.1 & -0.5 to $-0.1^{\star \star}$ \\
\hline \multicolumn{4}{|l|}{ Factors associated with less fatigue } \\
\hline Emotional functioning (PedsQL GCS, range 0-100) & 0.2 & 0.2 & 0.1 to $0.3^{* *}$ \\
\hline \multicolumn{4}{|l|}{ Model 3. Social factors ( $n=413$, adj. R2 $50.0 \%)$} \\
\hline \multicolumn{4}{|l|}{ Factors associated with more fatigue } \\
\hline Pressure at school (0-4; 'not at all' to 'a lot') & -5.5 & -0.2 & -7.4 to $-3.5^{\star \star}$ \\
\hline Being bullied (0-5; never to several times per week) & 4.7 & 0.1 & 1.9 to $7.5^{\star \star}$ \\
\hline \multicolumn{4}{|l|}{ Factors associated with less fatigue } \\
\hline Communication at home (1-5, higher score=better communication) & -1.2 & -0.0 & -4.3 to 1.9 \\
\hline Support at home $(1-7$, higher score=more support) & 1.6 & 0.1 & -0.5 to 3.7 \\
\hline Support by friends (1-7, higher score=more support) & 0.2 & 0.0 & -1.2 to 1.6 \\
\hline Social functioning (PedsQL GCS subscale, range 0-100) & 0.8 & 0.6 & 0.7 to $1.0^{* *}$ \\
\hline Member of a sports team or club ( $0=$ not a member, $1=$ member $)$ & 1.8 & 0.0 & -1.6 to 5.3 \\
\hline \multicolumn{4}{|l|}{ Factors not associated with fatigue in this sample } \\
\hline Screen time per day (hours/day) & -0.9 & -0.1 & -2.1 to 0.3 \\
\hline
\end{tabular}

In all models, fatigue is the dependent variable. Models are adjusted for age and sex of the child. The PedsQL MFS is scored on a scale from 0 to 100 , with a lower score indicating more severe fatigue. Thus, a negative correlation indicates a lower score, thus indicating more fatigue. ${ }^{*} \mathrm{P}<0.05,{ }^{* *} \mathrm{p}<0.01$.

PCS-C, Pain Catastrophising Scale for Children; PedsQL GCS, PedsQL Generic Core Scale; PedsQL MFS, PedsQL Multidimensional Fatigue Scale; RCADS, Revised Child Anxiety and Depression Scale; VAS, Visual Analogue Scale.

overlap in the variance explained by generic biological/ lifestyle, psychological and social factors, suggesting a strong interaction between these domains. Importantly, however, we found no significant difference between disease groups with respect to the association between fatigue and generic biological/lifestyle, psychological or social factors. Taken together, these findings call for a transdiagnostic approach to fatigue in children with chronic disease, taking into account the generic biological/lifestyle, psychological and social domains.

Fatigue is highly prevalent among children with chronic disease. ${ }^{2}$ The similarity among disease groups with respect to fatigue is in line with the results of Menting et al, who studied fatigue among adults with chronic disease. ${ }^{10}$ Our regression models based on separate domains revealed several moderate effect sizes and one large effect size. However, the final model comprised all three domains revealed one moderate and two small effect sizes for depressive symptoms, physical functioning and social functioning, respectively. In the final composite model, all three domains-biological/lifestyle, psychological and social-were still represented, emphasising the importance of all three domains in assessing fatigue.

With respect to generic biological/lifestyle factors, our finding that physical functioning, sleep and pain play a role in fatigue is consistent with previous studies involving paediatric JIA, CF and postcancer treatment patients. ${ }^{3-728}$ Encouraging the child to, for example, engage in a healthy lifestyle and participate in sports may be beneficial on a biological and social level, thereby reducing fatigue. ${ }^{28-30}$ This is likely true for fatigued children who are in a stable phase of their chronic disease, as well as other patient populations who suffer from fatigue, for example, following COVID-19. ${ }^{14}$ 
Table 5 Complete model including all generic biological/lifestyle, psychological and social factors and fatigue (PedsQL MFS general fatigue scale) as the dependent variable for the entire group of children with chronic disease ( $\mathrm{N}=357)$

\begin{tabular}{|c|c|c|c|}
\hline Associated factors & Unstandardised $\beta$ & Effect size & $95 \% \mathrm{Cl}$ \\
\hline \multicolumn{4}{|l|}{ Age and sex } \\
\hline Age & -0.9 & -0.1 & -1.3 to $-0.4^{\star \star}$ \\
\hline Sex & 1.0 & 0.0 & -1.7 to 3.7 \\
\hline \multicolumn{4}{|l|}{ Biological/lifestyle factors } \\
\hline \multicolumn{4}{|l|}{ Factors associated with more fatigue } \\
\hline Pain (VAS, range 0-10) & -0.5 & -0.1 & -1.1 to 0.1 \\
\hline Difficulties getting to sleep ( $0-5$; 'never' to 'almost every day') & 0.5 & 0.0 & -0.5 to 1.6 \\
\hline \multicolumn{4}{|l|}{ Factors associated with less fatigue } \\
\hline No of days physically active/week (0-7) & 0.4 & 0.0 & -0.2 to 1.0 \\
\hline Physical functioning (PedsQL GCS subscale, range 0-100) & 0.3 & 0.3 & 0.2 to $0.4^{\star \star}$ \\
\hline \multicolumn{4}{|l|}{ Psychological factors } \\
\hline \multicolumn{4}{|l|}{ Factors associated with more fatigue } \\
\hline Depressive symptoms (RCADS, range 0-30) & -2.6 & -0.5 & -3.1 to $-2.1^{\star \star}$ \\
\hline Anxiety level (RCADS, range 0-111) & 0.2 & 0.1 & 0.0 to $0.3^{*}$ \\
\hline Pain catastrophising (PCS-C, range 0-52) & 0.0 & 0.0 & -0.2 to 0.2 \\
\hline \multicolumn{4}{|l|}{ Factors associated with less fatigue } \\
\hline Emotional functioning (PedsQL GCS, range 0-100) & 0.1 & 0.1 & -0.0 to 0.2 \\
\hline \multicolumn{4}{|l|}{ Social factors } \\
\hline \multicolumn{4}{|l|}{ Factors associated with more fatigue } \\
\hline Pressure at school (0-4; 'not at all' to 'a lot') & -2.8 & -0.1 & -4.4 to $-1.2^{\star \star}$ \\
\hline Being bullied ( $0-5$; never to several times per week) & 1.7 & 0.0 & -0.5 to 3.9 \\
\hline \multicolumn{4}{|l|}{ Factors associated with less fatigue } \\
\hline Communication at home $(1-5$, higher score=better communication) & -0.1 & -0.0 & -2.5 to 2.3 \\
\hline Support at home (1-7, higher score=more support) & -0.4 & -0.0 & -2.0 to 1.3 \\
\hline Support by friends (1-7, higher score=more support) & 0.0 & 0.0 & -1.1 to 1.2 \\
\hline Social functioning (PedsQL GCS subscale, range $0-100$ ) & 0.2 & 0.2 & 0.1 to $0.3^{\star \star}$ \\
\hline Member of a sports team or club ( $0=$ not a member, $1=$ member $)$ & -1.7 & -0.0 & -4.4 to 1.1 \\
\hline \multicolumn{4}{|l|}{ Factors not associated with fatigue in this sample } \\
\hline Screen time per day (hours/day) & -0.2 & -0.0 & -1.2 to 0.8 \\
\hline
\end{tabular}

The PedsQL MFS is scored on a scale from 0 to 100 , with a lower score indicating more severe fatigue. Thus, a negative correlation indicates a lower score, thus indicating more fatigue.

${ }^{*} \mathrm{P}<0.05,{ }^{* *} \mathrm{p}<0.01$.

PCS-C, Pain Catastrophising Scale for Children; PedsQL GCS, PedsQL Generic Core Scale; PedsQL MFS, PedsQL Multidimensional Fatigue Scale; RCADS, Revised Child Anxiety and Depression Scale; VAS, Visual Analogue Scale.

With respect to the psychological domain, modifiable factors such as depression and/or anxiety—both of which are associated with fatigue-were also identified in other studies regarding chronic disease. ${ }^{12} 13$ These factors are suitable targets for treatment, for example, with cognitive behavioural therapy. ${ }^{31}$

The social context of developing children plays another important role in fatigue. ${ }^{29} 32$ We found that social functioning is significantly associated with fatigue, which is consistent with a recent finding that children with a chronic disease generally encounter more difficulties and achieve psychosocial milestones at a later age compared with healthy peers. ${ }^{29}$ Unfortunately, our study cannot distinguish whether poorer social functioning precedes or is a consequence of fatigue or whether the two perpetuate one another. Encouraging these children to engage in social participation and helping them selfmanage their disease may empower them to cope with their disease, possibly reducing fatigue. ${ }^{33}$ In assessing social context, proxy reports are highly relevant and may help reveal contributing factors that are not necessarily taken into account in these models. Thus, future studies should include proxy reports and the effect of the child's social network. Interestingly, we found that 'being bullied' was not significantly associated with fatigue, even though chronically ill children are more likely to 
be bullied compared with healthy peers. ${ }^{34}$ One possible explanation for this finding is that being bullied may have been under-reported, as the reported prevalence of bullying varies among reporting methods. ${ }^{35}$ Another possible explanation is that asking only one question regarding bullying may be inadequate for scoring the factor 'being bullied'.

A clear strength of this study is that we structurally assessed potentially modifiable generic biological/ lifestyle, psychological and social factors in a range of paediatric chronic diseases, with both congenital and acquired diseases and both life-threatening and nonlife-threatening diseases. Thus, our analysis revealed which factors can explain a relatively high degree of the reported variance in fatigue. Moreover, the majority of factors were significantly associated with fatigue, even after we adjusted for multiple testing.

Despite these strengths, our study has several limitations that warrant discussion. First, the participation rate was approximately $50 \%$, and approximately $18 \%$ of the participants did not complete the assessments in their entirety. However, we found no apparent difference between participants and non-participants or between completers and non-completers. Nevertheless, we cannot rule out the possibility that the non-participants were more severely ill or more fatigued, even though this was not the main reason given by the children who chose not to participate. In addition, some patient groups may have been under-represented, for example, children with a brain tumour. Finally, the study was designed to determine which biopsychosocial factors are associated with fatigue, but was not designed to identify causal relationships between the biopsychosocial factors and fatigue.

Because fatigue is both prevalent and distressing, it should be assessed as a multidimensional problem by monitoring the presence of fatigue and potentially modifiable fatigue-related factors in a multidisciplinary setting. Completing simple, validated questionnaires via a web-based portal is both time-efficient and compatible with outpatient care ${ }^{3036}$ Moreover, our finding that older children reported higher levels of fatigue are consistent with previous reports. ${ }^{27}$ It may be beneficial to monitor a child's fatigue from an early age in order to signal possible problems in time, possibly preventing deterioration and impaired functioning.

Although the presence of fatigue did not appear to differ significantly between disease groups, its associated perpetuating biopsychosocial factors can differ between individuals and can change over time. Thus, future studies should use a person-centred approach in order to develop customised interventions designed to help each patient self-manage his/her fatigue, for example, using ecological momentary assessments. ${ }^{37}$

\section{CONCLUSIONS}

Fatigue is a multidimensional concept across various childhood chronic diseases, with strong, overlapping and potentially modifiable factors in the biological, psychological and social domains. A transdiagnostic approach that takes into account these factors is therefore preferred for monitoring and treating fatigue in these patients.

Acknowledgements The authors would like to acknowledge the contributions of the patients and parents who participated in this study, as well as the caregivers who helped enrol the patients and discussed the outcomes of the questionnaires with them. The authors also thank Emma Berkelbach van der Sprenkel, Lotte Meijerink, Pleun Terpstra, Eline Albers, Martine van Grotel, Marloes van Gorp, Sophie van Baar, Annelieke Schoen, and Tijs Verdegaal for their help with the data collection. The authors also thank Dr C.F. Barrett for his assistance with English language editing.

Contributors MMN-vdV collected and analysed the data and wrote the manuscript. SLN designed the study, coordinated and supervised the data collection and helped write the manuscript. EMvdP, MAG, KvdE and GWD designed and supervised the data collection and interpretation, and helped write the manuscript. MMvdH-E and JFS critically reviewed the data analyses and helped write the manuscript. All authors approved the final submitted manuscript and agree to be accountable for all aspects of the work.

Funding The authors have not declared a specific grant for this research from any funding agency in the public, commercial or not-for-profit sectors.

Competing interests None declared.

Patient and public involvement Patients and/or the public were involved in the design, or conduct, or reporting, or dissemination plans of this research. Refer to the Methods section for further details.

Patient consent for publication Not required.

Ethics approval This study was classified by the Institutional Review Board as exempt from the Medical Research Involving Human Subjects Act (16-707/C).

Provenance and peer review Not commissioned; externally peer reviewed.

Data availability statement Data are available on reasonable request. Please contact the corresponding author for any data requests.

Open access This is an open access article distributed in accordance with the Creative Commons Attribution Non Commercial (CC BY-NC 4.0) license, which permits others to distribute, remix, adapt, build upon this work non-commercially, and license their derivative works on different terms, provided the original work is properly cited, appropriate credit is given, any changes made indicated, and the use is non-commercial. See: http://creativecommons.org/licenses/by-nc/4.0/.

ORCID iD

Merel M Nap-van der Vlist http://orcid.org/0000-0002-7911-8516

\section{REFERENCES}

1 Armbrust W, Siers NE, Lelieveld OTHM, et al. Fatigue in patients with juvenile idiopathic arthritis: a systematic review of the literature. Semin Arthritis Rheum 2016;45:587-95.

2 Nap-van der Vlist MM, Dalmeijer GW, Grootenhuis MA, et al. Fatigue in childhood chronic disease. Arch Dis Child 2019;104:1090-5.

3 Walter LM, Nixon GM, Davey MJ, et al. Sleep and fatigue in pediatric oncology: a review of the literature. Sleep Med Rev 2015;24:71-82.

4 Nijhof LN, van de Putte EM, Wulffraat NM, et al. Prevalence of severe fatigue among adolescents with pediatric rheumatic diseases. Arthritis Care Res 2016;68:108-14.

5 Nap-van der Vlist MM, Burghard M, Hulzebos HJ, et al. Prevalence of severe fatigue among adults with cystic fibrosis: a single center study. J Cyst Fibros 2018;17:368-74.

6 Langeveld NE, Grootenhuis MA, Voûte PA, et al. No excess fatigue in young adult survivors of childhood cancer. Eur J Cancer 2003;39:204-14.

7 Van Dijk-Lokkart EM, Steur LMH, Braam KI, et al. Longitudinal development of cancer-related fatigue and physical activity in childhood cancer patients. Pediatr Blood Cancer 2019;66:e27949.

8 Van de Vijver E, Van Gils A, Beckers L, et al. Fatigue in children and adolescents with inflammatory bowel disease. World J Gastroenterol 2019;25:632-43.

9 Engel GL. The need for a new medical model: a challenge for biomedicine. Science 1977;196:129-36.

10 Menting J, Tack CJ, Bleijenberg G, et al. Is fatigue a diseasespecific or generic symptom in chronic medical conditions? Health Psychology 2018;37:530-43. 
11 Stein RE, Jessop DJ. What diagnosis does not tell: the case for a noncategorical approach to chronic illness in childhood. Soc Sci Med 1989;29:769-78.

12 Jarad NA, Sequeiros IM, Patel P, et al. Fatigue in cystic fibrosis: a novel prospective study investigating subjective and objective factors associated with fatigue. Chron Respir Dis 2012;9:241-9.

13 Daniel LC, Brumley LD, Schwartz LA. Fatigue in adolescents with cancer compared to healthy adolescents. Pediatr Blood Cancer 2013;60:1902-7.

14 Garrigues E, Janvier P, Kherabi Y, et al. Post-discharge persistent symptoms and health-related quality of life after hospitalization for COVID-19. J Infect 2020;81:e4-6.

15 Gordijn MS, Suzanne Gordijn M, Cremers EMP, et al. Fatigue in children: reliability and validity of the Dutch PedsQL ${ }^{\text {TM multidimensiona }}$ fatigue scale. Qual Life Res 2011;20:1103-8.

16 Quanjer PH, Stanojevic S, Cole TJ, et al. Multi-ethnic reference values for spirometry for the 3-95-yr age range: the global lung function 2012 equations. Eur Respir J 2012;40:1324-43.

17 McErlane F, Foster HE, Carrasco R, et al. Trends in paediatric rheumatology referral times and disease activity indices over a ten-year period among children and young people with juvenile idiopathic arthritis: results from the childhood arthritis prospective study. Rheumatology 2016;55:1225-34.

18 Rosier EM, ladarola MJ, Coghill RC. Reproducibility of pain measurement and pain perception. Pain 2002;98:205-16.

19 Currie C, Zanotti C, Morgan A. Social determinants of health and well-being among young people. Copenhagen: World Health Organization Regional Office for Europe, 2012.

20 de Looze M, van Dorsselaer S, de Roos S. Health Behaviour in School Children 2013 - Health, Wellbeing and Education of Dutch Children, 2013.

21 Ng K, Hämylä R, Tynjälä J, et al. Test-retest reliability of adolescents' self-reported physical activity item in two consecutive surveys. Arch Public Health 2019;77.

22 WHO. Global recommendations on physical activity for health. WHO, 2015.

23 Engelen V, Haentjens MM, Detmar SB, et al. Health related quality of life of Dutch children: psychometric properties of the PedsQL in the Netherlands. BMC Pediatr 2009;9:68.

24 de Onis M, Onyango AW, Borghi E, et al. Development of a WHO growth reference for school-aged children and adolescents. Bull World Health Organ 2007;85:660-7.

25 Kösters MP, Chinapaw MJM, Zwaanswijk M, et al. Structure, reliability, and validity of the revised child anxiety and depression scale (RCADS) in a multi-ethnic urban sample of Dutch children. BMC Psychiatry 2015;15:132.

26 Crombez G, Bijttebier P, Eccleston C, et al. The child version of the pain catastrophizing scale (PCS-C): a preliminary validation. Pain 2003;104:639-46.

27 ter Wolbeek M, van Doornen LJP, Kavelaars A, et al. Severe fatigue in adolescents: a common phenomenon? Pediatrics 2006;117:e1078-86.

28 Armbrust W, Lelieveld OHTM, Tuinstra J, et al. Fatigue in patients with juvenile idiopathic arthritis: relationship to perceived health, physical health, self-efficacy, and participation. Pediatr Rheumatol Online J 2016;14:65

29 Maurice-Stam H, Nijhof SL, Monninkhof AS, et al. Review about the impact of growing up with a chronic disease showed delays achieving psychosocial milestones. Acta Paediatr 2019;108:2157-69.

30 Robinson PD, Oberoi S, Tomlinson D, et al. Management of fatigue in children and adolescents with cancer and in paediatric recipients of haemopoietic stem-cell transplants: a clinical practice guideline. Lancet Child Adolesc Health 2018;2:371-8.

31 Thabrew H, Stasiak K, Hetrick SE, et al. Psychological therapies for anxiety and depression in children and adolescents with long-term physical conditions. Cochrane Database Syst Rev 2018;12:CD012488.

32 Pinquart M, Teubert D. Academic, physical, and social functioning of children and adolescents with chronic physical illness: a metaanalysis. J Pediatr Psychol 2012;37:376-89.

33 Schmidt S, Petersen C, Bullinger M. Coping with chronic disease from the perspective of children and adolescents--a conceptual framework and its implications for participation. Child Care Health Dev 2003;29:63-75.

34 Pinquart M. Systematic review: bullying involvement of children with and without chronic physical illness and/or Physical/Sensory Disability-a meta-analytic comparison with Healthy/Nondisabled peers. J Pediatr Psychol 2017;42:245-59.

35 Sawyer AL, Bradshaw CP, O'Brennan LM. Examining ethnic, gender, and developmental differences in the way children report being a victim of "bullying" on self-report measures. J Adolesc Health 2008;43:106-14.

36 Haverman L, van Rossum MAJ, van Veenendaal M, et al. Effectiveness of a web-based application to monitor health-related quality of life. Pediatrics 2013;131:e533-43.

37 Bolger N, Davis A, Rafaeli E. Diary methods: capturing life as it is lived. Annu Rev Psychol 2003;54:579-616. 